\title{
Aterros sanitários para geração de energia elétrica a partir da produção de biogás no Brasil: comparação dos modelos LandGEM (EPA) e Biogás (Cetesb) ${ }^{\star}$
}

\author{
Jean Agustin Velásquez Piñas ** \\ Osvaldo Jose Venturini ${ }^{\star \star \star}$ \\ Electo Eduardo Silva Lora*** \\ Michele Aparecida de Oliveira*** \\ Orly Denisse Calle Roalcaba ${ }^{\star \star \star \star \star \star}$
}

\begin{abstract}
Atualmente existe preocupação em relação aos impactos ambientais provocados pela produção de resíduos sólidos, o que contribui para incrementar as mudanças climáticas já em curso. Ao serem dispostos em aterros sanitários, os resíduos sólidos geram biogás, produto da decomposição anaeróbica dos compostos orgânicos de origem animal ou vegetal. $\mathrm{Na}$ presente nota de pesquisa se faz uma estimação da quantidade de biogás e energia gerada da decomposição anaeróbica em um aterro sanitário na cidade de Três Corações, Minas Gerais. Para realizar a estimação dos parâmetros foram utilizados os modelos LandGEM (EPA) e Biogás (Cetesb), que mostraram resultados similares no momento de fazer a comparação, com uma variação de apenas $5 \%$ para ambos os modelos. Para o LandGEM, nos 20 anos de vida útil do aterro sanitário, existe uma produção de biogás acumulada de $26.075 .960 \mathrm{~m}^{3}$, com uma energia acumulada de 128,68 GWh e potência média de geração de 242 kW. Para o modelo Biogás, a produção acumulada é de $27.476 .360 \mathrm{~m}^{3}$, com uma energia acumulada de 141,31 GWh, para uma potência média de geração de $255 \mathrm{~kW}$.
\end{abstract}

Palavras-chaves: Aterro sanitário. Resíduos sólidos urbanos (RSU). Gás de aterro sanitário. Fontes renováveis. Geração de energia. Biogás.

\footnotetext{
* Os autores agradecem à Coordenação de Aperfeiçoamento do Ensino Superior (Capes), ao Conselho Nacional de Desenvolvimento Científico e Tecnológico (CNPq), à Fundação de Apoio da Pesquisa do Estado de Minas Gerais (Fapemig) e ao Núcleo de Excelência em Geração Térmica e Distribuída (Nest) pela colaboração no desenvolvimento deste trabalho.

** Núcleo de Excelência em Geração Termelétrica e Distribuída (Nest), Instituto de Engenharia Mecânica, Universidade Federal de Itajubá (Unifei), Itajubá-MG, Brasil (jean.velasquezp@gmail.com).

*** Núcleo de Excelência em Geração Termelétrica e Distribuída (Nest), Instituto de Engenharia Mecânica, Universidade Federal de Itajubá (Unifei), Itajubá-MG, Brasil (osvaldo@unifei.edu.br).

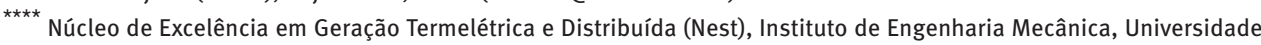
Federal de Itajubá (Unifei), Itajubá-MG, Brasil (electo@unifei.edu.br).

***** Instituto de Recursos Naturais (IRN), Universidade Federal de Itajubá (Unifei), Itajubá-MG, Brasil (chelyoli@yahoo. com.br).

${ }_{\star \star \star \star \star \star \star}$ Consultora independiente (orlydenisse@gmail.com).
} 


\section{Introdução}

A energia, nas suas mais diversas formas, é indispensável para a sobrevivência da espécie humana. E, mais do que sobreviver, o homem procurou sempre evoluir, descobrindo fontes e maneiras alternativas de adaptação ao ambiente em que vive e de atendimento às suas necessidades. Dessa forma, a exaustão, a escassez ou a inconveniência de um dado recurso tendem a ser compensadas pelo surgimento de outro. Em termos de suprimento energético, a eletricidade tornou-se uma das formas mais versáteis e convenientes de energia, passando a ser recurso indispensável e estratégico para o desenvolvimento socioeconômico de muitos países e regiões (ANEEL, 2005).

Esse desenvolvimento econômico e o consumo crescente das fontes de energia vêm provocando um desequilíbrio ambiental no planeta. Se não houver um grande esforço mundial no redirecionamento das nossas atividades produtivas, a qualidade de vida das próximas gerações e a sobrevivência da nossa espécie estarão comprometidas.

Neste contexto, a utilização de fontes alternativas de energia, em particular o biogás, aparece como uma oportunidade de particular importância para colaborar na oferta de energia do sistema interligado do Brasil, na forma de geração descentralizada e próxima aos pontos de consumo, por meio de equipamentos e combustível nacionais (exemplo resíduos de processo), vantagens estas que, aliadas aos benefícios ambientais amplamente conhecidos, fazem com que o biogás seja uma opção estratégica para o país, dependendo apenas de políticas adequadas para sua viabilização (MARÇON; ZUKOWSKI JR.; CAVALCANTE, 2004).

0 biogás, por sua vez, traz impactos positivos ao meio ambiente, com destaque para a mitigação de emissão de carbono da atmosfera, resultando em um balanço neutro do carbono durante o processo de produção de energia elétrica, o que contribui para a redução do efeito estufa. Isso ocorre porque todo gás carbônico produzido durante este processo é absorvido pelas plantas, que serão utilizadas novamente no processo, mantendo a concentração do gás carbônico atmosférico inalterável (BRANCO, 2010).

O Brasil já possui certa vantagem neste sentido, pois conta com uma das matrizes energéticas mais limpas do mundo. Do total de energia consumida no país, aquela proveniente de fontes renováveis varia de $61 \%$ a $41 \%$, sendo este último o valor mais aproximado do atual, enquanto no mundo $22,2 \%$ da energia advém de fontes renováveis e $77,8 \%$ de não renováveis (FREITAS; MAKIYA, 2012).

\section{Geração de biogás em aterros sanitários}

No caso do aterro sanitário, o biogás gerado não pode ser emitido para a atmosfera, devido ao seu alto percentual de metano, gás com potencial de aquecimento global 21 vezes superior ao do dióxido de carbono. Dessa forma, análises econômicas são necessárias para estudar a viabilidade financeira de empreendimentos energéticos em aterros sanitários. 
Um aterro de resíduos sólidos pode ser considerado um reator biológico, onde as principais entradas são os resíduos e a água e as principais saídas são os gases e o chorume. A decomposição da matéria orgânica ocorre por dois processos: a decomposição aeróbia, que acontece normalmente no período de deposição do resíduo; e, posteriormente, a decomposição anaeróbica, proveniente da redução do $\mathrm{CO}_{2}$ presente nos resíduos.

0 gás de aterro é composto por vários gases, sendo alguns em grandes quantidades, como o metano e o dióxido de carbono, e outros em pequenas quantidades (traços). Os gases presentes nos aterros de resíduos incluem metano $\left(\mathrm{CH}_{4}\right)$, dióxido de carbono $\left(\mathrm{CO}_{2}\right)$, amônia $\left(\mathrm{NH}_{3}\right)$, hidrogênio $\left(\mathrm{H}_{2}\right)$, gás sulfídrico $\left(\mathrm{H}_{2} \mathrm{~S}\right)$, nitrogênio $\left(\mathrm{N}_{2}\right)$ e oxigênio $\left(\mathrm{O}_{2}\right)$. 0 metano e o dióxido de carbono são os principais gases originários da decomposição anaeróbia dos compostos biodegradáveis dos resíduos orgânicos. A distribuição exata do percentual de gases variará conforme o tempo de existência do aterro.

Segundo o Ministério do Meio Ambiente (BRASIL, s/d), o objetivo do aproveitamento energético do biogás produzido pela degradação dos resíduos é convertê-lo em uma forma de energia útil, tais como eletricidade, vapor, combustível para caldeiras ou fogões, combustível veicular ou para abastecer gasodutos com gás de qualidade. Independentemente do uso final do biogás produzido no aterro, deve-se projetar um sistema padrão de coleta, tratamento e queima do biogás: poços de coleta, sistema de condução, tratamento (inclusive para desumidificar o gás), compressor e flare com queima controlada para garantia de maior eficiência de queima do metano. Há diversos projetos de aproveitamento energético no Brasil, como, por exemplo, nos aterros Bandeirantes e São João, no município de São Paulo, que já produzem energia elétrica.

\section{Modelos para determinar produção de biogás em aterros sanitários}

Existem vários modelos para determinar a produção de biogás em aterros sanitários e a energia gerada pela combustão do metano, que geralmente utilizam equações matemáticas, devendo-se tomar o cuidado de considerar certos critérios antes de empregar os programas, para se chegar a resultados confiáveis. Tais resultados servem para avaliar tanto o potencial de emissões de GEE (gases de efeito estufa) como a viabilidade de projetos de aproveitamento do biogás (SILVA, 2012).

A seguir, apresentam-se dois modelos para estimar geração de biogás.

Modelo de geração LandGEM (EPA, 2005)

$Q_{C H_{4}}=\sum_{i=1}^{n} \sum_{j=0,1}^{1} k L_{o}\left(\frac{M_{t}}{10}\right) e^{-k t_{i, j}}$

Onde:

$\mathrm{Q}_{\mathrm{CH}_{4}}=$ geração anual de metano no ano do cálculo (m³/ano);

$\mathrm{i}=$ incremento de tempo de 1 ano; 
$\mathrm{n}=$ (ano do cálculo) - (ano inicial do cálculo);

$\mathrm{j}=$ incremento de tempo de 0,1 ano;

$\mathrm{k}=$ taxa de geração de metano;

$\mathrm{L}_{\mathrm{o}}=$ capacidade potencial de geração de metano $\left(\mathrm{m}^{3} / \mathrm{Mg}\right) ;$

$\mathrm{M}_{\mathrm{t}}=$ massa de resíduos aceitada do enésimo ano $\mathrm{Mg}$;

$\mathrm{T}_{i, j}=$ idade da j-ésima seção de massa de resíduo Mi, aceita no enésimo ano (anos em número decimal, p. ex. 3,2 anos).

Modelo de geração Biogás (CETESB, 2006)

$\sum Q_{x}=k L_{o} \sum\left(R_{x} e^{-k(x-T)}\right)$

$\int \frac{d Q}{d t}=k R_{x} L_{O}$

$Q_{x}=k R_{x} L_{0} e^{-k(x-T)}$

Onde:

$\mathrm{Q}_{x}$ = vazão de metano $\left(\mathrm{m}^{3} \mathrm{CH}_{4} /\right.$ ano);

$\mathrm{k}=$ constante de decaimento (1/ano);

$\mathrm{L}_{0}=$ potencial de geração de biogás $\left(\mathrm{m}^{3} / \mathrm{kg}\right)$;

$\mathrm{R}_{x}=$ fluxo de resíduos (t/ano);

$\mathrm{x}=$ ano atual;

$\mathrm{T}=$ ano de deposição do resíduo.

\section{Metodologia}

O estudo foi desenvolvido no Município de Três Corações, localizado no Estado de Minas Gerais, para o qual se realizou uma estimativa do crescimento populacional com base em dados históricos dos censos e contagem populacional, do IGBE - Instituto Brasileiro de Geografia e Estatística.

Estima-se a projeção populacional para um período de 20 anos por meio do modelo de crescimento logístico, em que os parâmetros $a$ e $b$ da equação são estimados mediante regressão linear na forma log-log (MAMBELI BARROS, 2012).

$$
\begin{aligned}
& P(t)=k_{s}\left[\frac{e^{(a+b t)}}{1+e^{(a+b t)}}\right] \\
& \ln \left[\frac{\frac{P(t)}{k_{s}}}{1-\frac{P(t)}{k_{s}}}\right]=a+b t
\end{aligned}
$$


Onde:

$\mathrm{P}(\mathrm{t})=$ população em tempo $\mathrm{t}$;

ks = valor máximo de $\mathrm{P}$ (população de saturação);

$\mathrm{a}$ e $\mathrm{b}=$ coeficientes de regressão;

$\mathrm{t}=$ tempo (anos).

Para o cálculo da geração de resíduos sólidos, considera-se o índice de geração per capita de RSU (resíduos sólidos urbanos). Cabe mencionar que, no município de Três Corações, o índice per capita em 2010, 2011 e 2012 manteve-se entre 0,5 e 0,7 kg/hab./dia e, em 2013, aumentou para 1,5 kg/hab./dia (BRASIL, 2011, 2012, 2013, 2014). Tal variação pode ter ocorrido em função de atividades que não são responsáveis pelo crescimento normal do índice. Por esse motivo, estimou-se uma geração per capita do município de Três Corações de $0,75 \mathrm{~kg} / \mathrm{hab}$./dia para fazer a projeção com uma taxa de crescimento per capita de $1 \%$ anual.

Para fazer a comparação do potencial teórico da geração de energia a partir da combustão do biogás de aterro sanitário, foram utilizados dois modelos: o LandGEM e o Biogás (TIAGO FILHO et al., 2011).

O procedimento consiste no ingresso de dados de geração de RSU para os dois modelos (LandGEM e Biogás), que fazem projeções da quantidade de biogás gerada ao longo da vida do aterro sanitário. Posteriormente são comparados os resultados dos dois modelos e estima-se a energia possível de ser gerada.

Para a estimativa da potência disponível e da potência com motor de combustão interna (Internal Combustion Engine), utilizam-se as seguintes formulas:

$P_{x}=\frac{Q_{x} P_{c} \text { (metano) }}{31.536 .000} E_{c} \frac{k}{1.000}$

Onde:

$\mathrm{P}_{x}=$ potência disponível a cada ano $(\mathrm{kW})$;

$\mathrm{Q}_{x}=$ vazão de metano a cada ano;

$\mathrm{E}_{c}=$ eficiência de coleta de gases (\%);

31.536 .000 = número de segundos em um ano (s/ano);

$1 / 1000=$ para transformação de unidade de $\mathrm{J} / \mathrm{s}$ para $\mathrm{kW}$;

$\mathrm{K}=\mathrm{k}=1,000$;

$\mathrm{P}_{c}($ metano $)=$ poder calorífico do metano $\left(35,53 \times 10^{3} \mathrm{~J} / \mathrm{m}^{3} \mathrm{CH}_{4}\right)$.

$P_{I C E}=P_{x} E_{I C E}$

Onde:

$\mathrm{P}_{\text {ICE }}=$ potência elétrica com motor de combustão interna ( $\mathrm{kW}$ );

$\mathrm{P}_{x}=$ potência disponível a cada ano $(\mathrm{kW})$;

$\mathrm{E}_{I C E}=$ eficiência de motor de combustão interna. 


\section{Resultados e análises}

Para a análise do crescimento populacional, foram utilizados dados dos Censos Demográficos e Contagens Populacionais, do IBGE, considerando o modelo de crescimento logístico com uma população de saturação de 130.000 habitantes. Também foram assumidos valores da vida útil do aterro sanitário de 20 anos e taxa de coleta dos resíduos sólidos urbanos de $100 \%$. Além disso, os dados de potencial de geração de metano, taxa de geração de metano e a eficiência do motor de combustão são dados médios que podem modificar-se dependendo das características dos RSU e da quantidade de metano gerada.

TABELA 1

Dados utilizados para estimativa de crescimento populacional Município de Três Corações-MG

\begin{tabular}{lc}
\hline \multicolumn{1}{c}{ Variáveis } & Valores \\
\hline População urbana em 2015 - ano 1 (habitantes) & 69.618 \\
Quantidade de RSU produzida em 2010 (toneladas) & 19.058 \\
Índice de geração de RSU per capita (kg/hab./dia) & 0,75 \\
Índice de geração de RSU per capita (t/hab./ano) & 0,27 \\
Vida útil do aterro (anos) & 20 \\
Taxa de coleta dos RSU (\%) & 100,0 \\
Taxa de capitação do biogás no aterro (\%) & 50,0 \\
Potencial de geração de metano - $\mathrm{L}_{0}-\left(\mathrm{m}^{3} \mathrm{Ce}_{\mathrm{CH}}\right)$ & 170 \\
Taxa de geração de metano $(\mathrm{k})$ & 0,05 \\
Motor a combustão interna a pistão $(\%)$ & 33,0 \\
\hline
\end{tabular}

Fonte: IBGE. Censo Demográfico 1991, 2000 e 2010; Contagem Populacional 1996 e 2007; Projeção 2011, 2012; Programas LandGEM e Biogás.

No Gráfico 1, pode-se observar que a evolução da população total em Três Corações, segundo a curva de crescimento logístico, incrementa-se de 76.151 habitantes em 2014 (ano zero) para 91.311 habitantes (ano 20), considerando-se uma população de saturação de 130.000 habitantes.

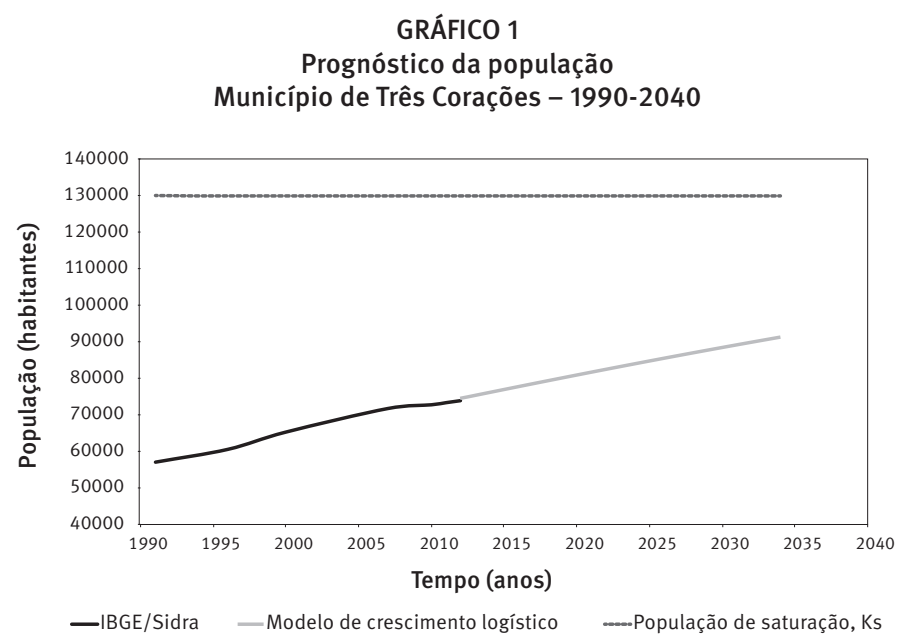

Fonte: IBGE. Censo Demográfico 1991, 2000 e 2010; Contagem Populacional 1996 e 2007; Projeção 2011, 2012; Programas LandGEM e Biogás. 
Para fazer a projeção da quantidade de biogás gerada em aterros sanitários segundo a população de uma cidade, é necessário ter como referência a população urbana. Assim, estimou-se a população urbana na cidade Três Corações (BRASIL, 2011, 2012, 2013, 2014).

Na Tabela 2, pode-se ver a quantidade anual de resíduos gerada na cidade de Três Corações, considerando um acréscimo de $1 \%$ do índice de geração per capita em relação ao ano anterior.

TABELA 2

Prognóstico de quantidade de biogás gerada por ano em aterro sanitário Município de Três Corações - 2015-2034

\begin{tabular}{lcccc}
\hline Ano (t) & $\begin{array}{c}\text { População } \\
\text { (habitantes) }\end{array}$ & $\begin{array}{c}\text { População } \\
\text { urbana } \\
\text { (habitantes) }\end{array}$ & $\begin{array}{c}\text { Índice per capita de massa } \\
\text { coletada, com acréscimo de } \\
\text { 1\% ao ano (kg/hab./dia) }\end{array}$ & $\begin{array}{c}\text { Quantidade anual coletada } \\
\text { de resíduos sólidos urbanos } \\
\text { (t/ano) }\end{array}$ \\
\hline 2015 & 76.957 & 69.618 & 0,75 & 19.058 \\
2016 & 77.759 & 70.343 & 0,76 & 19.449 \\
2017 & 78.557 & 71.065 & 0,77 & 19.845 \\
2018 & 79.351 & 71.784 & 0,77 & 20.246 \\
2019 & 80.141 & 72.498 & 0,78 & 20.652 \\
2020 & 80.925 & 73.208 & 0,79 & 21.063 \\
2021 & 81.705 & 73.913 & 0,80 & 21.479 \\
2022 & 82.480 & 74.614 & 0,80 & 21.899 \\
2023 & 83.249 & 75.310 & 0,81 & 22.324 \\
2024 & 84.013 & 76.001 & 0,82 & 22.755 \\
2025 & 84.772 & 76.687 & 0,83 & 23.189 \\
2026 & 85.524 & 77.368 & 0,84 & 23.629 \\
2027 & 86.270 & 78.043 & 0,85 & 24.074 \\
2028 & 87.010 & 78.712 & 0,85 & 24.523 \\
2029 & 87.744 & 79.376 & 0,86 & 24.977 \\
2030 & 88.471 & 80.034 & 0,87 & 25.436 \\
2031 & 89.192 & 80.686 & 0,88 & 25.900 \\
2032 & 89.905 & 81.331 & 0,89 & 26.368 \\
2033 & 90.612 & 81.970 & 0,90 & 26.841 \\
2034 & 91.311 & 82.603 & 0,91 & 27.319 \\
\hline
\end{tabular}

Fonte: IBGE. Censo Demográfico 1991, 2000 e 2010; Contagem Populacional 1996 e 2007; Projeção 2011, 2012; Programas LandGEM e Biogás.

Estimativa de emissões de metano de aterro sanitário por meio do software LandGEM (EPA)

A estimativa de emissões utilizando o software LandGEM resulta em dados das emissões para os principais gases gerados pela decomposição anaeróbia de resíduos sólidos urbanos, dos quais o metano é o que tem o poder calorífico necessário para a combustão e geração de energia.

O Gráfico 2 mostra o aumento das emissões geradas pelo aterro sanitário por meio da digestão anaeróbia, que alcançam seu valor máximo em 2035, com 4.686 toneladas de dióxido de carbono, 73 toneladas de NMOC (compostos orgânicos não metânicos) e 1.708 toneladas de metano. 


\section{GRÁFICO 2}

Estimativa de emissões dos principais gases de aterro sanitário

Município de Três Corações - 2015-2155

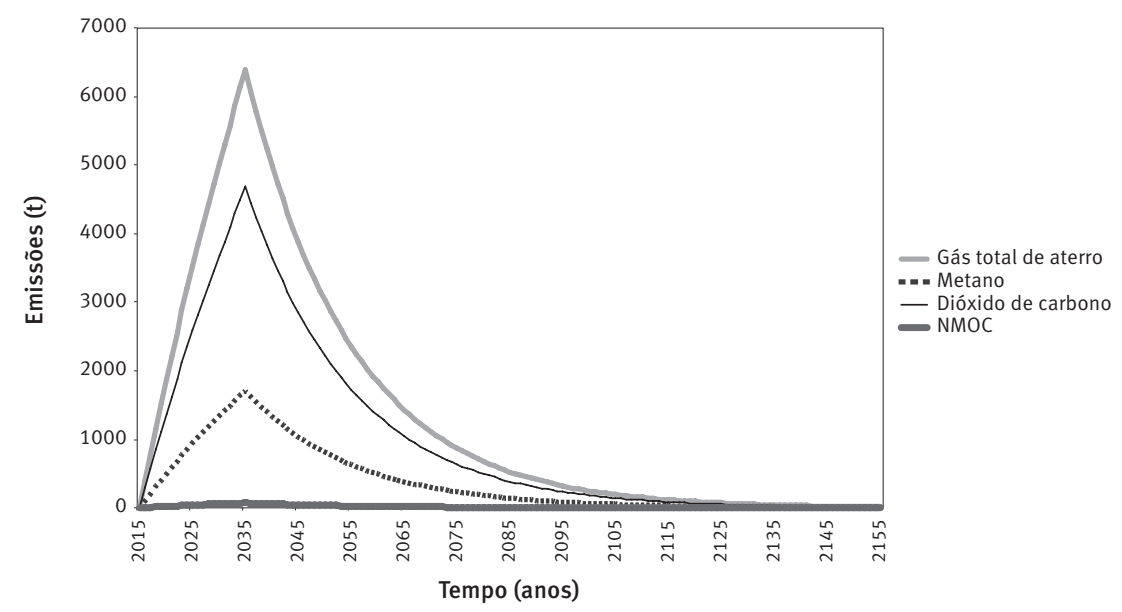

Fonte: IBGE. Censo Demográfico 1991, 2000 e 2010; Contagem Populacional 1996 e 2007; Projeção 2011, 2012; Programas LandGEM e Biogás.

No Gráfico 3, observa-se a produção de metano em aterro sanitário, atingindo 26.075.960 $\mathrm{m}^{3}$ até o final da vida útil do aterro. A partir daí a quantidade começa a diminuir porque se deixa de incorporar matéria orgânica ao aterro sanitário.

\section{GRÁFICO 3}

Estimativa de emissões de metano (modelo LandGEM) em aterro sanitário Município de Três Corações - 2015-2155

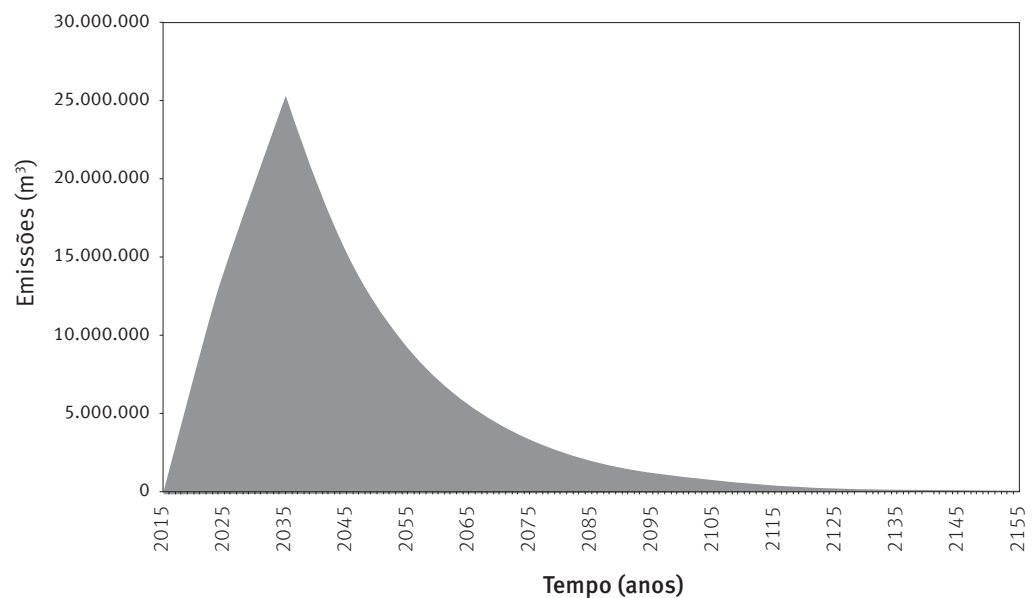

Fonte: IBGE. Censo Demográfico 1991, 2000 e 2010; Contagem Populacional 1996 e 2007; Projeção 2011, 2012; Programas LandGEM e Biogás. 
Estimativa de emissões de metano de aterro sanitário por meio do software Biogás (Cetesb)

O software Biogás gera dados apenas de emissões de metano pela decomposição anaeróbia dos resíduos sólidos urbanos. A característica deste software é permitir a geração de potência a partir dos dados ingressados de população.

0 Gráfico 4 mostra que a produção de metano gerada no aterro sanitário chega a 27.476.360 $\mathrm{m}^{3}$ até o encerramento do aterro sanitário, diminuindo depois desse período, da mesma forma que no modelo LandGEM, devido ao fato de não ser depositada matéria orgânica no aterro sanitário.

\section{GRÁFICO 4}

Estimativa de emissões de metano (modelo Biogás) em aterro sanitário Município de Três Corações - 2015-2051

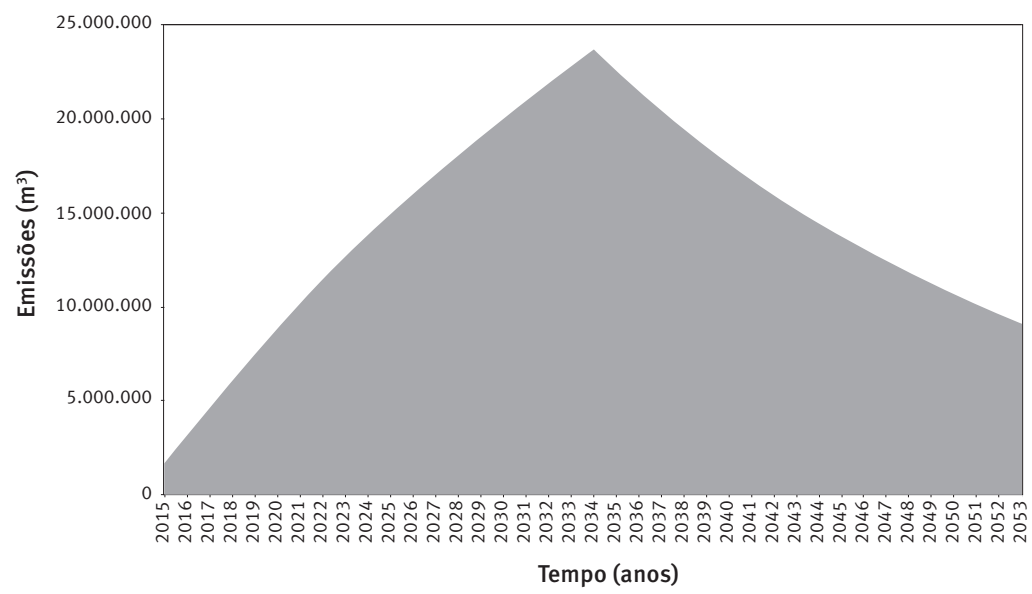

Fonte: Cetesb (2006).

Comparação de geração de metano e potência gerada dos modelos LandGEM (EPA) e Biogás (Cetesb)

Pode-se observar, na Tabela 3, que não existe diferença significativa entre os dois modelos utilizados para calcular a geração do biogás de aterros sanitários, porque ambos utilizam equações lineares (SILVA, 2012).

O Gráfico 5 mostra a comparação da geração de energia dos dois modelos, com energia acumulada durante 20 anos de 128,68 GWh, para o LandGEM, e de 141,31 GWh, para o Biogás, sendo que, para uma geração de energia elétrica utilizando um motor de combustão interna a pistão, o qual tem uma eficiência de $33 \%$, pode haver uma potência média de $242 \mathrm{kWe}$, com o primeiro modelo, e de $255 \mathrm{kWe}$, com o segundo. A variação de dados do LandGEM e Biogás é de aproximadamente $5 \%$. 
TABELA 3

Acumulado de geração de metano, energia e médias anuais de potência gerada dos modelos LandGEM

(EPA) e Biogás (Cetesb) em aterro sanitário

Município de Três Corações - 2015-2034

\begin{tabular}{|c|c|c|c|c|}
\hline \multirow[b]{2}{*}{ Modelo } & \multirow{2}{*}{$\begin{array}{c}\text { Emissões de } \\
\text { metano } \\
\left(\mathrm{m}^{3} / \text { ano }\right)\end{array}$} & \multirow{2}{*}{$\begin{array}{c}\text { Energia } \\
\text { acumulada } \\
(\text { GWh })\end{array}$} & \multicolumn{2}{|c|}{ Potência (kWe) } \\
\hline & & & Disponível & $\begin{array}{l}\text { Motor de combustão } \\
\text { interna a pistão }\end{array}$ \\
\hline LandGEM (EPA) & 26.075 .960 & 128,68 & 734 & 242 \\
\hline Biogás (Cetesb) & 27.476 .360 & 141,31 & 774 & 255 \\
\hline Variação (\%) & \multicolumn{4}{|c|}{5,37} \\
\hline
\end{tabular}

Fonte: EPA, 2005; CETESB, 2006.

GRÁFICO 5

Estimativa de potência de geração de energia com um motor de combustão interna a pistão em aterro sanitário

Município de Três Corações - 2015-2051

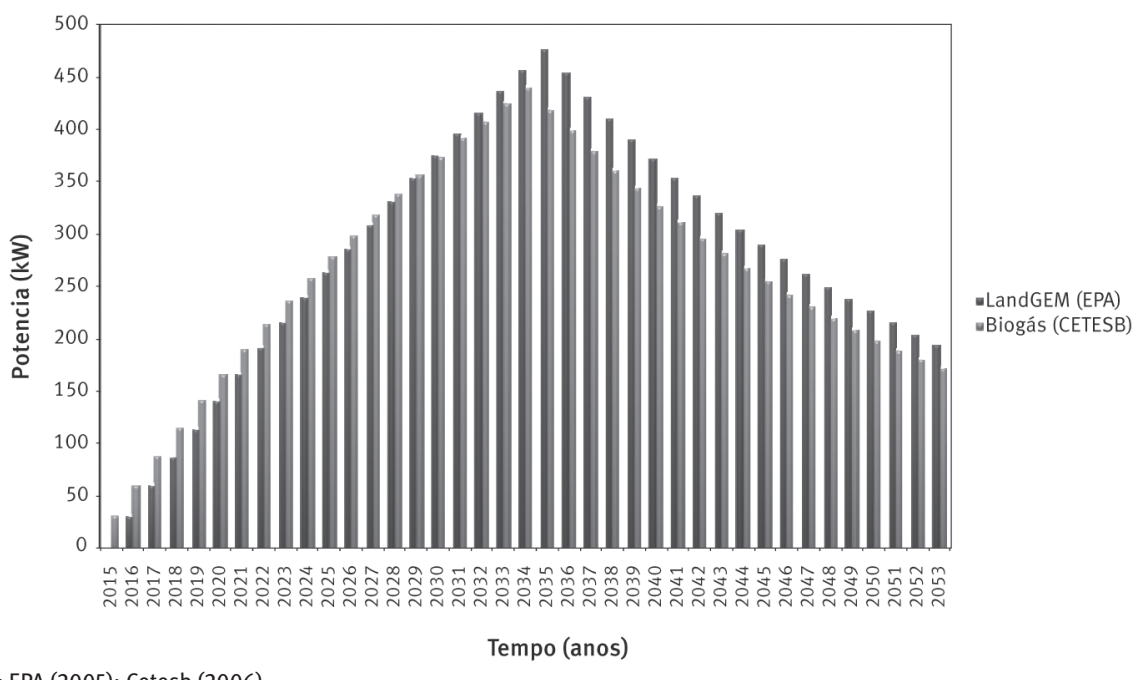

Fonte: EPA (2005); Cetesb (2006).

\section{Conclusões}

A produção de biogás acumulada em 20 anos foi de $26.075 .960 \mathrm{~m}^{3}$ para modelo LandGEM e de $27.476 .360 \mathrm{~m}^{3}$ para o Biogás, com 128,68 GWh e 141,31 GWh de energia acumulada, respectivamente.

A potência média da geração foi de 242 kWe utilizando o LandGEM e de 255 kWe com o modelo Biogás, para um motor de combustão interna a pistão com eficiência de conversão elétrica de $33 \%$.

A utilização energética de metano é a melhor forma para geração de energia elétrica, já que, por um lado, se deixa de emitir gases de efeito estufa e, por outro, se obtém um benefício econômico, ao poupar energia elétrica ou pela venda à rede elétrica. 
Os dois modelos utilizados para fazer a análise de geração de energia são muito similares quanto aos resultados, mas possuem certas diferenças na quantidade do metano gerado nos primeiros anos, mas a diferença vai desaparecendo ao chegar ao final da vida útil do aterro.

O ponto máximo de geração de metano para os dois modelos é aos 20 anos, momento no qual o aterro sanitário se encerra e deixa de incorporar matéria orgânica que gere digestão anaeróbia.

A variação média dos modelos LandGEM e Biogás é de aproximadamente $5 \%$, porque os dois modelos são lineares, não tendo diferença significativa no momento de fazer a análise, podendo-se concluir-se que a utilização dos dois modelos levará a resultados similares.

\section{Referências}

ANEEL - Agência Nacional de Energia. Atlas de energia elétrica do Brasil. 2. ed. Brasilia: Aneel, 2005. BRANCO, M. S. R. C. Avaliação do impacto da presença de siloxanos em sistemas de aproveitamento de biogás. 142 fl. Dissertação (Mestrado) - Universidade Nova de Lisboa, Lisboa, 2010.

BRASIL. Ministério do Meio Ambiente. Aproveitamento energético do biogás de aterro sanitário. Brasília, s/d. Disponível em: 〈http://www.mma.gov.br/cidades-sustentaveis/residuos-solidos/ politica-nacional-de-residuos-solidos/aproveitamento-energetico-do-biogas-de-aterrosanitario>. Acesso em: 3 dez. 2014.

. Ministério das Cidades. Secretaria Nacional de Saneamento Ambiental. Sistema Nacional de Informações sobre Saneamento - SNIS. Diagnóstico do manejo de resíduos sólidos urbanos - 2009. Brasília, 2011.

Ministério das Cidades. Secretaria Nacional de Saneamento Ambiental. Sistema Nacional de Informações sobre Saneamento - SNIS. Diagnóstico do manejo de resíduos sólidos urbanos - 2010. Brasília, 2012.

Ministério das Cidades. Secretaria Nacional de Sanemento Ambiental. Sistema Nacional de Informações sobre Saneamento - SNIS. Diagnóstico do manejo de resíduos sólidos urbanos - 2011. Brasília, 2013.

- Ministério das Cidades. Secretaria Nacional de Sanemento Ambiental. Sistema Nacional de Informações sobre Saneamento - SNIS. Diagnóstico do manejo de resíduos sólidos urbanos - 2012. Brasília, 2014.

CETESB - Companhia Ambiental do Estado de São Paulo. Biogás: geração e uso energético versão 1.0/Cetesb. São Paulo, 2006. Disponível em: 〈http://www.cetesb.sp.gov.br/mudancasclimaticas/biogas/Softwares/16-Softwares\#〉. Acesso em: 12 nov. 2014.

EPA - United States Environmental Protection Agency. Landfill gas emissions model (LandGEM) Version 3.02. 2005. Disponivel em: 〈http://www.epa.gov/ttn/catc/products.html〉. Acesso em: 5 nov. 2014.

FREITAS, C. O. de; MAKIYA, I. K. Potencial energético a partir do biogás proveniente de aterros sanitários do Estado de São Paulo. In:XXXII ENCONTRO NACIONAL DE ENGENHARIA DE PRODUCAO. Desenvolvimento Sustentável e Responsabilidade Social: as contribuições da engenharia de produção. Anais... Bento Gonçalves-RS, 2012.

IBGE - Instituto Brasileiro de Geografia e Estatística. Censo Demográfico 1991. Rio de Janeiro, 1992. 
Contagem Populacional 1996. Rio de Janeiro, 1997.

Censo Demográfico 2000. Rio de Janeiro, 2001.

Contagem Populacional 2007. Rio de Janeiro, 2008.

Censo Demográfico 2010. Rio de Janeiro, 2011.

Projeção da população 2011, 2012. Rio de Janeiro, 2015.

MAMBELI BARROS, R. Tratado de resíduos sólidos. Rio de Janeiro: Interciência, 2012.

MARÇON, R. O.; ZUKOWSKI JR., J. C.; CAVALCANTE, I. R. L. Avaliação de planta térmica com biomassa (briquete de casca de arroz) - Caso Real Fazenda experimental do centro universitário Luterano de Palmas. In: $5^{\circ}$ ENCONTRO DE ENERGIA NO MEIO RURAL. Anais...Campinas: Unicamp, 2004. Disponivel em: 〈http://www.proceedings.scielo.br/scielo.php?pid=MSC000000002200 $4000100008 \&$ script=sci_arttext . Acesso em: 25 nov. 2014.

SILVA, T. R. Metodologia para a determinação teórica da potência ótima conseguida a partir da combustão do biogás gerado em aterro sanitário: estudo de caso do aterro sanitário de ItajubáMG. 161 fl. Dissertação (Mestrado) - Universidade Federal de Itajubá, Itajubá, 2012.

TIAGO FILHO, G. L. et al. Analysis of Brazilian SHP policy and its regulation scenario. Energy Policy, v. 39, n. 10, p. 6689-6697, 2011.

\section{Sobre os autores}

Jean Agustin Velásquez Piñas é mestrando em Engenharia de Energia da Universidade Federal de Itajubá - Unifei e pesquisador do Núcleo de Excelência em Geração Termelétrica e Distribuída - Nest, Instituto de Engenharia Mecânica.

Osvaldo Jose Venturini é doutor em Engenharia Mecânica pela Universidade Federal de Itajubá - Unifei e atua como professor da mesma Universidade. Foi pesquisador pela Fapemig 20122014 e bolsista de Produtividade em Pesquisa do CNPq - nível 2 e pesquisador do Núcleo de Excelência em Geração Termelétrica e Distribuída - Nest, Instituto de Engenharia Mecânica da Unifei.

Electo Eduardo Silva Lora é doutor em Construção de Geradores de Vapor e Reatores pela Universidade Politécnica de São Petersburgo, na Rússia. Atua como professor da Universidade Federal de Itajubá - Unifei, coordenador do Núcleo de Excelência em Geração Termelétrica e Distribuída - Nest, Instituto de Engenharia Mecânica e bolsista de Produtividade em Pesquisa do CNPq - nível $1 \mathrm{~B}$.

Michele Aparecida de Oliveira é mestranda em Engenharia de Energia da Universidade Federal de Itajubá - Unifei e pesquisadora do Instituto de Recursos Naturais - IRN.

Orly Denisse Calle Roalcaba é mestre em Bussines Administration (MBA) pela Southern Taiwan University of Science and Technology - República da China e atua como consultora em economia e desenvolvimento rural.

\section{Endereço para correspondência}

Jean Agustin Velásquez Piñas

Av. BPS, 1303

37500-903 - Itajubá-MG, Brasil 


\author{
Osvaldo Jose Venturini \\ Av. BPS, 1303 \\ 37500-903 - Itajubá-MG, Brasil \\ Electo Eduardo Silva Lora \\ Av. BPS, 1303 \\ 37500-903 - Itajubá-MG, Brasil \\ Michele Aparecida de Oliveira \\ Av. BPS, 1303 \\ 37500-903 - Itajubá-MG, Brasil \\ Orly Denisse Calle Roalcaba \\ Rua Mario Braz 94 \\ 37500-354 - Itajubá-MG, Brasil
}

\begin{abstract}
Landfills for electricity generation from biogas production in Brazil: comparison of LandGEM (EPA) and Biogas (Cetesb) models
\end{abstract}

Currently there is increasing concern about the environmental impacts generated by the production of solid waste, which helps to accelerate ongoing climate change. Solid wastes in landfills generate biogas as a product of anaerobic decomposition of organic compounds found in them. This research note estimates of the amount of biogas and energy generated by the anaerobic decomposition produced in a landfill in the city of Três Corações, Minas Gerais. To estimate these parameters, LandGEM (EPA) and BIOGAS (Cetesb) models were used. Both models showed similar results with a variation of only $5 \%$. LandGEM model shows an accumulative biogas production of $26,075,960 \mathrm{~m}^{3}$, with an accumulated energy of $128.68 \mathrm{GWh}$ and media power generation of $242 \mathrm{~kW}$. BIOGAS model shows an accumulative biogas production of $27,476,360 \mathrm{~m}^{3}$, with an accumulated energy of $141.31 \mathrm{GWh}$, for an average power generation of $255 \mathrm{~kW}$.

Keywords: Landfill. Municipal solid waste (MSW). Landfill gas. Renewable sources. Power generation. Biogas.

\title{
Resumen
}

Rellenos sanitarios para la generación de energía eléctrica a partir de la producción de Biogás en Brasil: comparación de los modelos LandGEM (EPA) y Biogás (Cetesb)

Actualmente existe preocupación en relación a los impactos ambientales provocados por la producción de residuos sólidos, lo cual contribuye a incrementar el cambio climático ya en curso. Al ser dispuestos en rellenos sanitarios, los residuos sólidos generan biogás como producto de la descomposición anaeróbica de los compuestos orgánicos de origen animal o vegetal. La presente nota de investigación busca hacer una estimación de la cantidad de biogás y energía generada de la descomposición anaeróbica dentro de un relleno sanitario en la ciudad de Três Corações, Minas Gerais. Para realizar la estimación de estos parámetros fueron utilizados los 
modelos LandGEM (EPA) e BIOGÁS (Cetesb), que muestran resultados similares al momento de hacer la comparación, con una variación de apenas $5 \%$ entre ambos modelos. Para LandGEM, en los 20 años de vida útil del relleno sanitario existe una producción de biogás acumulada de 26.075.960 $\mathrm{m}^{3}$, con una energía acumulada de 128,68 GWh y potencia media de generación de 242 kW. Para el modelo Biogás, la producción acumulada de biogás es de $27.476 .360 \mathrm{~m}^{3}$ con una energía acumulada de 141,31 GWh, para una potencia media de generación de 255 kW.

Palabras claves: Relleno sanitario. Residuos sólidos urbanos (RSU). Gas de relleno sanitario. Fuentes renovables. Generación energía. Biogás.

Recebido para publicação em 08/12/2015

Recomendado para publicação em 20/03/2016

Aceito para publicação em 09/04/2016 